\title{
Intracoronary Haematoma as a Manifestation of Spontaneous Coronary Artery Dissection
}

\author{
Felipe Maia ${ }^{1}$, César Medeiros², Cláudia Matos³, Leonardo Duarte ${ }^{4}$, Jacqueline Sampaio dos Santos 5 , \\ Denilsom C. Albuquerque ${ }^{6}$, Miguel A. N. Rati ${ }^{7}$
}

\begin{abstract}
The etiology of spontaneous coronary artery dissection has not been well clarified. Different studies associate it to pregnancy, physical stress, collagen diseases and vasculitis. In general, patients do not have the classic risk factors for coronary artery disease, which makes mandatory the suspicion of this condition, especially in young adults with acute coronary syndromes. We report the case of a 38-year-old female with non-ST segment elevation acute coronary syndrome and intracoronary hematoma with no apparent dissection, diagnosed by intravascular ultrasound, in the right coronary artery. There is no consensus so far on the best way to treat these cases.
\end{abstract}

DESCRIPTORS: Coronary vessels. Angioplasty. Stents. Myocardial infarction.

S pontaneous dissection of the coronary artery is a rare cause of acute coronary syndrome. When dissection occurs, it most often manifests as acute myocardial infarction with ST-segment elevation (STEMI) in patients such as women in the third trimester of pregnancy, in the postpartum period, or engaged in vigorous exercise, although it also affects men, to a lesser extent. Unlike intima dissection in coronary artery disease, the plane of dissection in spontaneous dissection is in the media or between the media and the adventitia. ${ }^{1}$

The ideal treatment remains unclear. Emergency coronary angiography to confirm the diagnosis is

\section{RESUMO}

Hematoma Intracoronário como Manifestação de Dissecção Espontânea de Artéria Coronária

A dissecção espontânea de artéria coronária é um quadro de etiologia ainda não bem esclarecida. Diferentes estudos associam essa entidade a período gestacional, estresse físico, doenças do colágeno e vasculites. Em geral, os pacientes não apresentam os fatores de risco clássicos para doença arterial coronária, o que torna obrigatória a suspeita dessa afecção, especialmente em adultos jovens com síndrome coronária aguda. Neste artigo relatamos o caso de paciente do sexo feminino, de 38 anos de idade, com síndrome coronária aguda sem supradesnivelamento do segmento ST e hematoma intracoronário sem dissecção aparente, diagnosticado pelo ultrassom intracoronário, em artéria coronária direita. Não existe, até o presente momento, consenso quanto à melhor forma de tratamento nesses casos.

DESCRITORES: Vasos coronários. Angioplastia. Stents. Infarto do miocárdio.

essential. Treatment strategy, whether clinical, surgical or percutaneous, is mainly based on clinical presentation, extent of the dissection, and the amount of ischaemic myocardium at risk. Patients who survive the initial presentation usually have a good prognosis. ${ }^{2}$

\section{CASE REPORT}

The case of a 38-year-old female patient with myocardial infarction with non-ST-segment elevation (NSTEMI) and without the classic risk factors for coronary artery disease is reported. She had a family history of one sister who died at 35 years of age from

\footnotetext{
1 Interventionist cardiologist physician at Hospital Quinta D'Or. Rio de Janeiro, RJ, Brazil

${ }^{2}$ Interventionist cardiologist physician at Hospital Quinta D'Or. Rio de Janeiro, RJ, Brazil.

3 Interventionist cardiologist physician at Hospital Quinta D'Or. Rio de Janeiro, RJ, Brazil.

${ }^{4}$ Interventionist cardiologist physician at Hospital Quinta D'Or. Rio de Janeiro, RJ, Brazil.

${ }^{5}$ Head physician of the Cardiology Sector of Hospital Quinta D'Or. Rio de Janeiro, RJ, Brazil.
}

\footnotetext{
${ }^{6}$ Doctor. Scientific coordinator of Instituto D'Or de Ensino e Pesquisa. Rio de Janeiro, RJ, Brazil.

${ }^{7}$ Director physician of the Interventionist Cardiology Service of Hospital Quinta D'Or. Rio de Janeiro, RJ, Brazil.
}

Correspondence to: Felipe Maia. Rua Vinícius de Moraes, 242 - ap 102 - Ipanema - Rio de Janeiro, RJ, Brazil - CEP 22411-010

E-mail: fe.maia@globo.com

Received on: 11/13/2012 • Accepted on: 1/30/2013 
myocardial infarction associated with spontaneous dissection of the left coronary artery. In the week prior to admission, she had observed the onset of progressive chest pain in distress, at vigorous/moderate exertion, with relief at rest. On the day of the admission, she had an episode of angina of greater intensity and no improvement at rest, at the end of an exercise class, when she sought the emergency room of this hospital, and was attended to with pain initiated for at least 20 minutes. The electrocardiogram (ECG) showed no ST-T changes, and troponin I was elevated (1.03 ng/mL, reference value $<0.034 \mathrm{ng} / \mathrm{mL}$ ). The patient received treatment for non-ST segment elevation myocardial infarction (NSTEMI), with acetylsalicylic acid $300 \mathrm{mg}$, clopidogrel $300 \mathrm{mg}$, and subcutaneous enoxaparin; early invasive stratification was indicated. A coronary angiography was performed by right radial access $(6 \mathrm{~F})$ within the first six hours of evolution, which showed preserved left ventricular function and end-diastolic volume, left coronary artery free of obstructive lesions, and right coronary artery with luminal narrowing from the middle third of the vessel, extending to the posterior ventricular and posterior descending branches, compromising up to $80 \%$ of the reference vessel diameter at the point of greatest narrowing (Figure1).

Since the vessel was not obstructed and the lesion morphology did not suggest atherothrombotic disease, the diagnostic hypothesis of spontaneous coronary artery dissection was made, although there was no line of dissection visible on the angiography. Therefore, it was decided to maintain the patient on medical treatment, but due to repeated episodes of angina during optimized anti-ischaemic treatment, a percutaneous coronary intervention (PCI) was scheduled for the following day, with three drug-eluting stents (bifurcation technique) guided by intravascular ultrasound (IVUS).

A Judkins right guiding catheter (7F) was chosen for greater support through the femoral artery, as the radial pulse did not appear to accept larger-calibre catheters. After intracoronary infusion of $40 \mathrm{mg}$ of isosorbide mononitrate, IVUS was performed with a
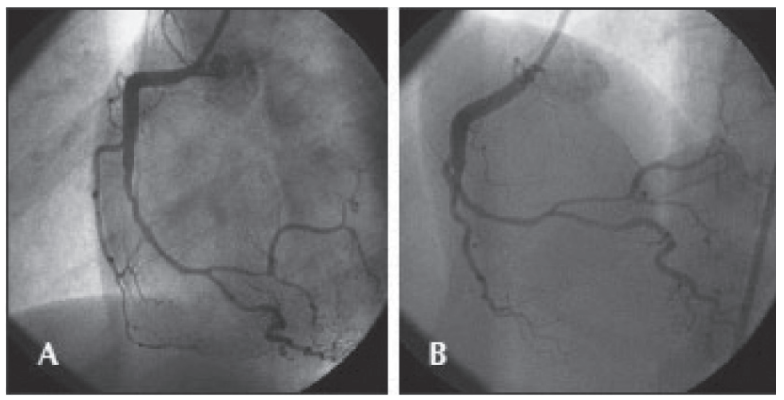

Figure 1 - In A, right coronary artery in left anterior oblique view with significant luminal narrowing from the middle third of the vessel. In B, the right coronary artery in anteroposterior cranial view with severe narrowing involving the middle and distal thirds, as well as the proximal segments of posterior ventricular and posterior descending branches.
20-MHz Eagle Eye ${ }^{\circledR}$ catheter (Volcano Corp. - Rancho Cordova, United States) into the posterior descending branch and right coronary artery, which showed an image suggestive of hematoma with length $>60 \mathrm{~mm}$ from the middle third of the right coronary artery to the middle segment of the posterior descending branch (Figure 2). The luminal area in the first third of the posterior descending branch was $2.9 \mathrm{~mm}^{2}$. The step crush bifurcation technique was chosen to treat the lesion. Initially, the ostium of the posterior ventricular branch was pre-dilated and a 2.5/20 mm everolimus-eluting stent was implanted in that branch. After crushing the stent struts with a semicompliant balloon in the right coronary artery, two more everolimus-eluting stents were implanted with overlapping struts $(3.0 / 32 \mathrm{~mm}$ and $4.0 / 38 \mathrm{~mm}$ ) in the distal and middle thirds of the right coronary artery. The procedure was finalized by recrossing the guide wire to the posterior ventricular branch and performing post-dilation using the kissing balloon technique. At the end of the $\mathrm{PCl}$, a new evaluation with IVUS of the posterior descending branch and right coronary artery showed stents with complete strut apposition, overlapping by $1 \mathrm{~mm}$ in the interposition area and well expanded (Figure 3 ). The procedure finished using an $8 \mathrm{~F}$ percutaneous closure device due to the presence of a small femoral hematoma.

The patient showed an uneventful hospital evolution without further episodes of chest pain during the six days of hospital stay. The inguinal hematoma showed no thrills or murmurs and the patient reported minimal local discomfort at the time of hospital discharge. At the 30-day and six-month follow-up by telephone contact after the event, the patient reported being asymptomatic.

\section{DISCUSSION}

Older case reports in the literature are heterogeneous, mixing aortic dissections associated with coronary artery disease ${ }^{1}$ and cases of spontaneous coronary artery dissection and intracoronary hematoma. Such findings are responsible for the wide variations in the incidence of this event, with a strong predominance of females, ${ }^{2-4}$ probably underestimated, considering
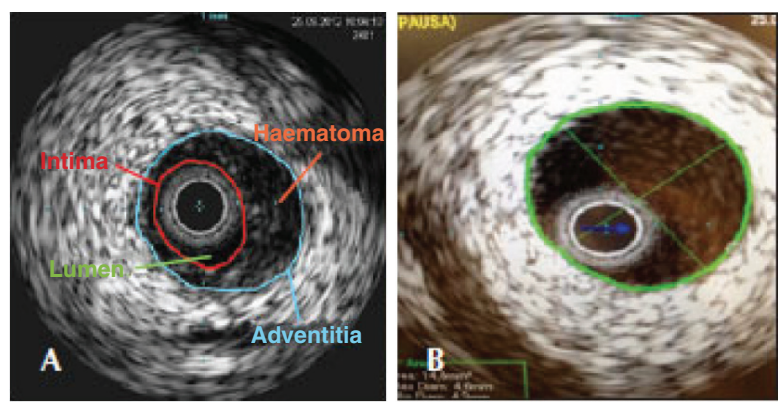

Figure 2 - In A, intracoronary ultrasound of the distal right coronary artery showing subintimal hematoma, causing significant luminal impairment. In B, intracoronary ultrasound of the proximal right coronary artery showing absence of atherothrombotic lesions. 
the cases of sudden death without anatomopathological evaluation and the less careful approach of young women with chest pain in emergency rooms in recent decades. Although both cases course with hematoma associated with vessel dissection, compressing the vessel lumen, pre-existing coronary artery disease is an exclusion factor for the diagnosis of spontaneous coronary artery dissection, according to some authors. ${ }^{5}$ In certain cases, as shown above, imaging techniques, such as IVUS and optical coherence tomography, are fundamental for the diagnosis, due to the absence of dissection line on the angiography.

Tweet et al. ${ }^{5}$ recently reported the largest cohort of patients with spontaneous coronary artery dissection $(\mathrm{n}=87)$, with a large predominance of females $(82 \%)$; STEMI was the most common clinical presentation (49\%), followed by NSTEMI (44\%), unstable angina (7\%), and malignant ventricular arrhythmias (14\%). The factors most frequently associated with spontaneous coronary artery dissection were the postpartum period in women and strenuous exercise in men. One in five

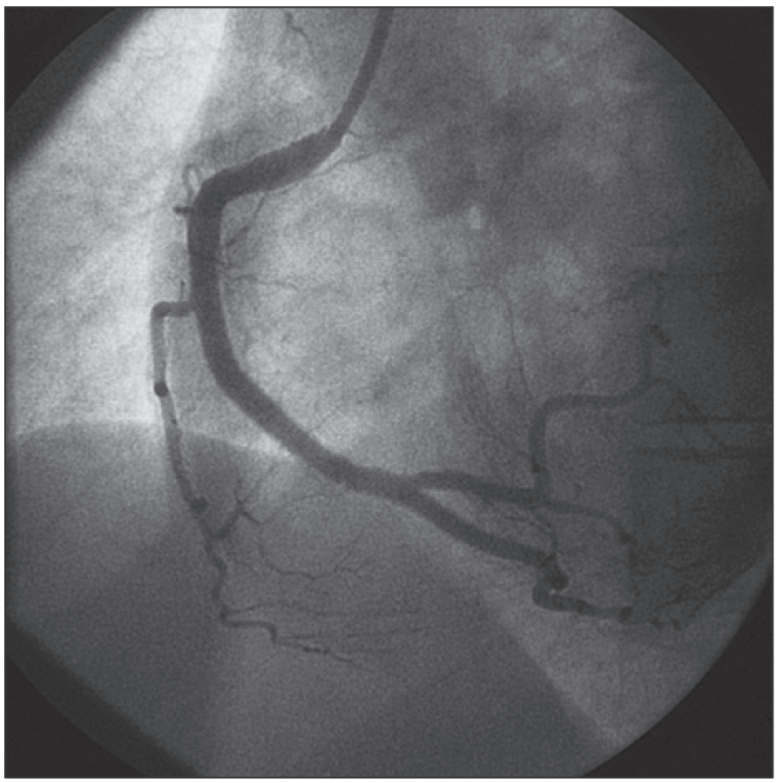

Figure 3 - Final control in the left anterior oblique view after the percutaneous coronary intervention with three everolimus-eluting stents to the right coronary artery and its branches. female patients had recurrence of spontaneous coronary artery dissection, unlike in males, in whom there was no recurrence at a mean follow up of 47 months. Despite the low mortality rate at one year $(1.1 \%)$ and 10 years $(7.7 \%)$ of follow-up, consistent with other records, ${ }^{4}$ the high $\mathrm{PCl}$ failure rate $(35 \%)$ is impressive and should be critically analyzed. The author ascribes the cause of failure to the difficulty in crossing the guide wire to the true lumen and/or the increase in area of dissection/ hematoma in an attempt to cross the lesion. Considering that these $\mathrm{PCl}$ s have been performed throughout the last three decades, these results should be superior when using more modern techniques and equipment. IVUS, for instance, was important in the present case to confirm the position of the guide in the true lumen and to rule out the presence of atherosclerotic disease in the treated segment. The most interesting finding in the study by Tweet et al. ${ }^{5}$ was the observation of fibromuscular media dysplasia in the iliac artery, incidentally diagnosed by the femoral angiography in eight of 16 patients who received percutaneous vascular occlusion devices, in addition to two other cases diagnosed in the carotid artery as cause of spontaneous dissection of this vessel. This noninflammatory vasculopathy has been observed in autopsies of patients who suffered sudden death. ${ }^{6}$

Pate et al. ${ }^{7}$ described, in 2005, a series of seven female patients with acute coronary syndrome who showed abrupt transition from luminal narrowing segments to normal coronary vessel on the coronary angiography. All had fibromuscular media dysplasia in the renal arteries, suggesting this vascular disease as the cause of the acute coronary syndrome. Another Canadian publication presented a series of six cases of female patients with spontaneous coronary artery dissection triggered by physical activity and with fibromuscular media dysplasia in other vascular territories, suggesting the possibility that this was the cause of the acute coronary syndrome. All cases were evaluated by optical coherence tomography, which, in addition to confirming the presence of intramural hematoma, provided more information regarding the morphological presentation spectrum of fibromuscular media dysplasia in the coronary artery, such as intimal thickening and presence of calcification. ${ }^{8}$ Unlike the classic radiographic pattern of fibromuscular media

Table 1

Characteristics of coronary damage in fibromuscular media dysplasia and coronary artery disease

\begin{tabular}{lcc}
\hline & Fibromuscular media dysplasia & Coronary artery disease \\
\hline Lesion location & Distal & Proximal \\
Morphology & Long and irregular & Variable \\
Limit & Well-defined & Difficult to define \\
Other coronary arteries & Free of disease & Lesions in other coronary arteries \\
\hline
\end{tabular}


dysplasia of the renal artery with "string of beads" appearance, this is not always present in coronary arteries. Table 1 presents the differentiating characteristics of coronary damage in fibromuscular media dysplasia and coronary artery disease.

A conservative approach is usually adopted in the management of spontaneous coronary artery dissection; revascularization is reserved for cases of persistent or recurrent ischemia. Alfonso et al. ${ }^{9}$ prospectively followed-up 45 cases of spontaneous coronary artery dissection $(40 \%$ associated with coronary artery disease), and demonstrated that revascularization was required in $35 \%$ of the series due to recurrence of symptoms during hospitalization. At a mean follow-up of 730 days, the longest retrieved in the literature for this type of patient, only one death from heart failure and two new cases of revascularization were observed. Regardless of the presence of coronary artery disease with or without spontaneous coronary artery dissection, the rate of event-free survival was $94 \%$ and $88 \%$, respectively. In this series of patients there was no association between spontaneous coronary artery dissection and inflammatory and/or immunological abnormalities.

The presence of acute coronary syndrome in young patients, particularly females without risk factors for coronary heart disease (even though they can be present), ${ }^{9}$ should raise the suspicion of spontaneous coronary artery dissection. ${ }^{10}$ This hypothesis is reinforced by the observation of an angiographically-detected dissection line or abrupt transition from a coronary vessel with normal appearance to segmental luminal narrowing, usually located in the mid-distal vessel segment. ${ }^{11}$ Some authors recommend not only the use of adjunct intracoronary imaging methods, such as IVUS and optical coherence tomography, ${ }^{12-15}$ to rule out the presence of atherothrombotic plaques (since the image on the angiography may be similar to coronary artery disease), but also imaging methods to discard the association with fibromuscular media dysplasia in other vascular territories, such as cerebral CT angiography and digital subtraction abdominal angiography. The case report by Ikegami et al. ${ }^{14}$ demonstrated, based on robust evidence, an intracoronary hematoma without intimal flap at the IVUS, and complete reabsorption of the hematoma with conservative treatment after evaluation with IVUS was repeated at 30 days.

Treatment without $\mathrm{PCI}$ should be attempted as the initial strategy in cases of coronary artery with Thrombolysis in Myocardial Infarction (TIMI) 3 flow and no ECG evidence of ST-segment elevation. PCI should be reserved for STEMI or ACSWSTE with decreased coronary flow and/or progressive or recurrent ischemia during optimized treatment with beta-blockers, coronary vasodilators, and antiplatelet agents.

\section{CONFLICT OF INTEREST}

The authors declare no conflicts of interest.

\section{REFERENCES}

1. Vasconcelos Filho FJ, Barreto JE, Barros RB, Queiroz IC, Lima RR. Dissecção espontânea de artéria coronária como causa de síndrome coronariana aguda. Arq Bras Cardiol. 2006;86(4):308-9.

2. Vrints CJ. Spontaneous coronary artery dissection. Heart. 2010;96(10):80-8.

3. Vanzetto G, Berger-Coz E, Barone-Rochette G, Chavanon O, Bouvaist $H$, Hacini R, et al. Prevalence, therapeutic management and medium-term prognosis of spontaneous coronary artery dissection: results from a database of 11,605 patients. Eur J Cardiothorac Surg. 2009;35(2):250-4.

4. Mortensen KH, Thuesen L, Kristensen IB, Christiansen EH. Spontaneous coronary artery dissection: a Western Denmark Heart Registry study. Catheter Cardiovasc Interv. 2009;74(5):710-7.

5. Tweet MS, Hayes SN, Pitta SR, Simari RD, Lerman A, Lennon RJ, et al. Clinical features, management and prognosis of spontaneous coronary artery dissection. Circulation. 2012;126(5):579-88.

6. Michaud K, Romain N, Brandt-Casadevall C, Mangin P. Sudden death related to small coronary artery disease. Am J Forensic Med Pathol. 2001;22(3):225-7.

7. Pate GE, Lowe R, Buller CE. Fibromuscular dysplasia of the coronary and renal arteries?. Catheter Cardiovasc Interv. 2005;64(2):138-45.

8. Saw J, Poulter R, Fung A, Wood D, Hamburger J, Buller CE. Spontaneous coronary artery dissection in patients with fibromuscular dysplasia: a case series. Circ Cardiovasc Interv. 2012;5(1):134-7.

9. Alfonso F, Paulo M, Lennie V, Dutary J, Bernardo E, JimenezQuevedo P, et al. Spontaneous coronary artery dissection: long-term follow-up of a large series of patients prospectively managed with a "conservative" therapeutic strategy. J Am Col Cardiol Interv. 2012;5(10):1062-70.

10. Saw J, Starovoytov A, Mancini J, Buller CE. Non-atherosclerotic coronary artery disease in young women. J Am Coll Cardiol. 2011;58 Suppl:B113.

11. Halon D, Sapoznikov D, Lewis B, Gotsman M. Localization of lesions in the coronary circulation. Am J Cardiol. 1983;52(8):921-6.

12. Maehara A, Mintz G, Castagna M, Pichard A, Satler L, Waksman R, et al. Intravascular ultrasound assessment of spontaneous coronary artery dissection. Am J Cardiol. 2002;89(9):466-7.

13. Ohlmann P, Weigold G, Kim S, Hassani S, Escolar E, Pichard A, et al. Spontaneous coronary dissection: computed tomography appearance and insights from intravascular ultrasound examination. Circulation. 2006;113(10):e403-5.

14. Ikegami R, Tsuchida K, Oda H. Acute myocardial infarction caused by spontaneous coronary intramural hematoma. Invasive Cardiol. 2012;24(12):692-3.

15. Iyisoy A, Celik M, Celik T, Yuksel UC. The role of intravascular ultrasound guidance in the treatment of intramural hematoma probably caused by spontaneous coronary artery dissection in a young woman with acute anterior myocardial infarction. Cardiol J. 2012;19(5):532-5. 